\title{
Having a word with yourself: Neural correlates of self-criticism and self-reassurance
}

\author{
Olivia Longe ${ }^{\mathrm{a}, *}$, Frances A. Maratos ${ }^{\mathrm{b}}$, Paul Gilbert ${ }^{\mathrm{c}}$, Gaynor Evans ${ }^{\mathrm{a}}$, Faye Volker ${ }^{\mathrm{a}}$, \\ Helen Rockliff ${ }^{c}$, Gina Rippon ${ }^{\mathrm{a}}$ \\ a School of Life and Health Sciences, Neurosciences Research, Aston University, Birmingham B4 7ET, UK \\ ${ }^{\mathrm{b}}$ Department of Psychology, University of Derby, Kedleston Road, Derby, DE22 1GB, UK \\ c Mental Health Research Unit, Kingsway Hospital, University of Derby, Derby, UK
}

\section{A R T I C L E I N F O}

\section{Article history:}

Received 2 June 2009

Revised 7 September 2009

Accepted 11 September 2009

Available online 18 September 2009

\begin{abstract}
A B S T R A C T
Self-criticism is strongly correlated with a range of psychopathologies, such as depression, eating disorders and anxiety. In contrast, self-reassurance is inversely associated with such psychopathologies. Despite the importance of self-judgements and evaluations, little is known about the neurophysiology of these internal processes. The current study therefore used a novel fMRI task to investigate the neuronal correlates of selfcriticism and self-reassurance. Participants were presented statements describing two types of scenario, with the instruction to either imagine being self-critical or self-reassuring in that situation. One scenario type focused on a personal setback, mistake or failure, which would elicit negative emotions, whilst the second was of a matched neutral event. Self-criticism was associated with activity in lateral prefrontal cortex (PFC) regions and dorsal anterior cingulate $(\mathrm{dAC})$, therefore linking self-critical thinking to error processing and resolution, and also behavioural inhibition. Self-reassurance was associated with left temporal pole and insula activation, suggesting that efforts to be self-reassuring engage similar regions to expressing compassion and empathy towards others. Additionally, we found a dorsal/ventral PFC divide between an individual's tendency to be self-critical or self-reassuring. Using multiple regression analyses, dorsolateral PFC activity was positively correlated with high levels of self-criticism (assessed via self-report measure), suggesting greater error processing and behavioural inhibition in such individuals. Ventrolateral PFC activity was positively correlated with high self-reassurance. Our findings may have implications for the neural basis of a range of mood disorders that are characterised by a preoccupation with personal mistakes and failures, and a self-critical response to such events.
\end{abstract}

(C) 2009 Elsevier Inc. All rights reserved.

\section{Introduction}

Self-criticism relates to a form of negative self-judgement and selfevaluation, which can be directed to various aspects of the self, such as one's physical appearance, behaviour, inner thoughts and emotions, personality and intellectual attributes (Gilbert, 2000, 2007). People can feel controlled and 'beaten down' by their own self-criticism. Research suggests that it is the strength of negative emotions especially (self) anger, disgust and contempt that may drive the pathogenic qualities of self-criticism (Whelton and Greenberg, 2005). In the last 20 years, self-criticism has been associated with a range of psychological disorders including: mood disorder (Blatt and Zuroff, 1992; Gilbert, 2000; Gilbert and Irons 2005; Teasdale and Cox, 2001), social anxiety (Cox et al., 2000), self-harm (Babiker and Arnold, 1997), anger and aggression (Gilbert and Miles, 2000; Tangney and Dearing, 2002) and post-traumatic stress disorder (Brewin, 2003; Lee, 2005). Furthermore, early onset of excessive self-criticism predicts later

\footnotetext{
* Corresponding author.

E-mail address: o.a.longe@aston.ac.uk (O. Longe).
}

psychological problems (Zuroff et al., 1994). In accordance with this, research by Irons et al. (2006) found that self-criticism and selfreassurance were significant mediators of the link between recall of parenting (e.g., rejecting vs. warm) and depression in a student population. Self-critics may also do less well with standard therapies (Rector et al., 2000).

In contrast to the findings on self-criticism, abilities to be selfreassuring and self-compassionate are negatively linked to psychopathology (Gilbert et al., 2004; Neff, 2003). The ability to be selfreassuring in the face of setbacks is believed to be the result of both temperament and early attachment experiences (Mikulincer and Shaver, 2007) and result in resilience (Masten, 2001). Furthermore, new developments in psychotherapy are beginning to focus on the possibility of training people in self-reassurance and self-compassion with beneficial effects (Gilbert and Irons, 2005; Gilbert and Procter, 2006; Leary et al., 2007; Lutz et al., 2008).

Gilbert (1989, 2000) and Gilbert and Irons (2005) suggested that self-criticism and self-reassurance may stimulate the same neurophysiological systems as criticism and reassurance generated externally, i.e., by others. This is no different in principle than our understanding that an external signal (say sexual or food) and an internal fantasy can 
both stimulate the appropriate (sexual or eating) arousal system. Indeed people use their imagination precisely to try to generate certain types of feeling and arousal (e.g. sexual fantasies). In addition neuroimaging studies of emotion often rely on people recalling or imagining having certain emotions (e.g. George et al., 1995). The implications of this are important because it implies that self-criticism and self-reassurance may become the internal stimulators and maintainers of key threat or reassurance linked neurophysiological circuits.

In regard to external compassion, Lutz et al. (2008) demonstrated that the meditative practice of compassion for others is associated with activation of limbic regions. Specifically, being in a 'lovingkindness-compassionate meditative state' whilst presented with the emotional sounds of others (particularly in a distressed state) was associated with increased insula and anterior cingulate cortex activation. If the same physiological systems are activated by both externally mediated (e.g. criticism or praise from others) and internally generated processes (self-generated criticism or praise) (Gilbert and Irons, 2005), then one might expect processes of selfcompassion/reassurance to engage the same brain regions as those involved in compassion for others; namely the insula and/or anterior cingulate cortex. However, the research is complex, because for people with high trait self-criticism the generation of selfreassuring/compassionate feelings can feel unfamiliar, fearful and even threatening (Gilbert, 2007, 2009). Using a measure of heart rate variability, Rockliff et al. (2008) found that those low in selfcriticism responded to compassionate imagery as if it was soothing and calming, whereas those high in self-criticism responded with threat type responses. Self-reassurance may therefore also be associated with activation in key components of the threat system e.g. the amygdala (LeDoux, 1998, 2000), in individuals with high levels of self-criticism.

When individuals make errors, or have particular faults or attributes that may court social disapproval, this can be perceived to be threatening to the self. Self-criticism could therefore be viewed as an attentional focusing on faults and errors, with a punitive response. Identifying self-criticism in terms of error monitoring, allows us to draw parallels with the more extensive neurophysiological literature on error processing. A number of neuroimaging studies have investigated the neuronal response to errors and typically associate lateral PFC (including dorsolateral prefrontal cortex; DLPFC) and dorsal anterior cingulate (dAC) activation with error detection. Additionally, the lateral PFC (including orbitofrontal cortex; OFC) has been associated with the inhibition of inappropriate behaviour and the facilitation of appropriate behaviour (Miller and Cohen, 2001). These findings fit well with that of increased DLPFC activation observed to external criticism (Hooley et al., 2005). Hooley et al. (2005) played taped statements of either maternal praise or maternal criticism to recovered depressed and healthy control participants. They found that control subjects showed bilateral activation of the DLPFC to both praise and criticism, whilst recovered depressed people had a similar response to maternal praise but negligible activation of DLPFC to criticism. However, these data may be compromised by small subject numbers and the fact that some of the recovered depressed participants were taking antidepressants (two out of seven) or had a history of antidepressant use.

As self-criticism and self-reassurance both contain aspects of selfreferencing and/or self-reflection, activations found in neuroimaging studies of these processes may additionally relate to our study. Typically activations to self-monitoring of current emotional states have been found in the anterior cingulate (BA32) (Gusnard et al., 2001, Frith and Frith, 1999) and also studies of self-reflection reveal anterior medial prefrontal activation (Johnson et al., 2002, 2006). More recently, significant neural activation in the anterior cingulate, medial prefrontal cortex, superior temporal gyrus and anterior insula was found to be associated with self-reflection (Modinos et al., 2009).
To date, there have been no studies specifically designed to explore the neurophysiology of self-criticism and self-reassurance. Given that self-criticism is involved in a whole range of psychopathologies, a better understanding of the neurophysiological mediators of selfcriticism may throw new light on vulnerability, maintenance and treatment aetiology factors implicated in such disorders.

The present fMRI study therefore used as stimuli, statements that were designed to describe a scenario which could be regarded as a personal failure or mistake, which would elicit shame-linked, negative emotions. Participants were asked to read these statements and imagine either their own self-critical 'voice' or self-reassuring 'voice' as it would respond in that situation. Participants were also presented with neutral statements as a control. In light of past findings on both error detection and external criticism, we hypothesised that processes of self-criticism would specifically be associated with activity in lateral PFC regions and dAC. As self-criticism can also be considered a form of self-punishment with associated negative emotions (Whelton and Greenberg, 2005), we further hypothesised amygdala and striatal activation (caudate and putamen) to self-criticism. Moreover, as observed to processes of compassion towards others, we proposed that self-reassurance would be associated with insula activation. We additionally sought to examine whether the neuronal activations observed would be correlated with scores on a self-report measure of self-criticism or self-reassurance using multiple regression analyses, and further hypothesised that lateral PFC and amygdala activation would be positively correlated with high self-criticism scores. Finally, we hypothesised that high selfreassurance scores would be correlated with insula activity.

\section{Method}

\section{Participants}

Seventeen female right-handed participants were recruited from Aston University student and staff population (mean age $\pm \mathrm{SD}=$ $24.71 \pm 4.21$ years). Only female participants were chosen so as to avoid any biases associated with gender. Also we intend to explore these processes in clinical populations with high trait self-criticism, and there is a higher ratio of women to men in such identified populations. Volunteers with a self-reported history of neurological or psychiatric disease and/or those scoring 15 on the Beck Depression Inventory (Beck et al., 1961) were excluded. We choose a higher than normal cut-off range for the BDI, as individuals with high selfcriticism are also likely to have mild depressive symptoms and we wanted a wide range of scores on the self-criticism self-report measure (below) to carry out our multiple regression analyses. The purpose and risks of the study were explained to all volunteers, who gave written informed consent to participate, as approved by the University Ethics Committee.

\section{Behavioural measures}

Prior to scanning, participants were required to complete a number of behavioural scales. Participants completed the Forms of Selfcriticising/Attacking and Self-reassurance Scale (FSCRS). The FSCRS is a 24-item self-report scale, which assesses participants' level of selfcriticising and self-reassuring thoughts (Gilbert et al., 2004). The forms of self-criticizing can be divided into two components related to i) "being self-critical, dwelling on mistakes and sense of inadequacy" (inadequate self; IS) and; ii) "wanting to hurt the self and feeling selfdisgust/hate" (hate self). Hated-self items are more strongly endorsed in clinical cases. In this study, hate self scores were so low as to suggest floor effects and were therefore not analysed further.

In addition, volunteers completed 2 different mood scales. The first of these, the Beck Depression Inventory (BDI), is a 21-item self-report rating scale, which measures characteristic attitudes and symptoms of depression (Beck et al., 1979, 1988). The second is the Center for 
Epidemiologic Studies-Depression Scale (CES-D), which is a 20-item scale, measuring a range of depressive symptomatology (such as depressed mood, feelings of guilt, sleep disturbance) in nonpsychiatric populations (Radloff, 1977).

\section{fMRI paradigm}

Participants were visually presented with a list of 120 statements, 60 that described a negative emotion scenario and 60 non-emotive neutral scenarios. For the negative emotion scenarios participants were asked to imagine scenarios that could be regarded as a personal failure, mistake or rejection i.e., a threat to self (TtS) and to elicit negative emotions e.g. "A third job rejection letter in a row arrives in the post". In contrast, a matched neutral scenario with similar semantic content that would not be expected to be a TtS or to elicit emotion was used, for example "The second free local newspaper in a row arrives in the post". For half of each statement type (TtS and neutral) participants were instructed to imagine themselves in that scenario and then either: 1 ) imagine being self-critical and what their self-critical thoughts would be, or 2) imagine being self-reassuring and what their self-reassuring thoughts would be. The design therefore was $2 \times 2$ factorial, with two categories of scenario (TtS and neutral) and two perspective categories (self-critical and self-reassuring).

Prior to the study taking place, the statements were pre-tested on a separate group of participants $(n=12)$ for how strong or intense both their self-critical and self-reassuring thoughts related to each scenario were. We asked participants to rate their self-critical/selfreassuring thoughts for each scenario using a 1-7 Likert scale, where in the first instance, 1 was 'not at all critical' and 7 was 'highly critical' and in the second instance, 1 was 'not at all reassured' and 7 was 'highly reassured'. The pre-test data, revealed a clear step divide between the TtS and neutral matched statements in terms of the selfcritical imagery scores. That is, the neutral statements ranged from 1 to $<2$ (i.e. not strong elicitors of self-criticism), whereas the TtS statements ranged from 3.3 to 6.9 (i.e. medium to strong elicitors of self-criticism). There was no clear difference between the neutral statements (scores ranged from 2.6 to 4.4 ) and TtS statements (scores ranged from 2.2 to 4.6 ) in terms of self-reassurance scores. The $60 \mathrm{TtS}$ scenario statements were then randomly assigned into one of the two 'perspective' categories (30 self-critical and 30 self-reassuring). The perspective categories were then checked to ensure they matched in terms of strength of imagability of self-critical and self-reassuring thoughts, in addition to length of statements and word frequency. The neutral matched statements were split in the same manner.

In the scanner the statements were presented in mini-blocks of 5 sentences. Before each block, an instruction screen was presented (1700 ms), which indicated the perspective to adopt (self-critical or self-reassuring). At the start of each trial a variable fixation (1-3 s) was displayed. Next, each statement was displayed for 9 s during which time participants read the statements and imagined the scenario from the indicated perspective. This was followed by a rating phase during which time subjects rated how intensely their self-critical or self-reassuring thoughts were to the statement by responding to a visual intensity rating scale. Here, a coloured bar appeared on the screen for $4 \mathrm{~s}$ which represented a scale from very low intensity on the left, to very high intensity on the right. Participants pressed a button to indicate the appropriate intensity they experienced. There was a $14 \mathrm{~s}$ recovery period after each block had been presented, and during this time a cross hair was presented on the screen. Prior to scanning participants had been instructed to try to relax and clear their mind during this rest phase. The scan session was divided into two runs to allow subjects a short rest. Each run was 18.66 min with approximately 2 min rest in between runs. Scan trial events are depicted in Fig. 1.

\section{Image acquisition and analysis}

Functional magnetic resonance imaging (fMRI) was carried out on a 3T Siemens Trio system at Aston University, using a T2* weighted gradient-echo EPI sequence (TR $=2.8 \mathrm{~s}, \mathrm{TE}=30 \mathrm{~ms}$, flip angle $90^{\circ}$, FOV $25 \times 25 \mathrm{~cm}$, matrix $64 \times 64)$. The images consisted of 40 axial slices, $3 \mathrm{~mm}$ thick $(128 \times 128$ in-plane resolution). To allow equilibrium to reach steady state, 2 dummy volumes were collected before the start of each run ( 400 volumes) and discarded before analysis. T1 weighted scans were acquired for anatomical localisation.

Analysis was performed using SPM2 (Wellcome Institute of Neurology, implemented in Matlab; Mathworks Inc., MA). Prior to model application, images were first slice-time corrected. Brain volumes from each participant were then realigned to the first volume to correct for head-motion. Functional images were next spatially normalised into a standard Montreal Neurological Institute (MNI) EPI template. Following this, spatial smoothing was applied with an isotropic Gaussian kernel filter of $10 \mathrm{~mm}$ full-width halfmaximum to facilitate inter-subject averaging.

First-level analysis was performed on each subject to generate a single mean image for each subject for every comparison between the 4 conditions of interest in a simple main effects analysis. These mean images were then combined in a second-level random effects analysis using one-sample $t$-tests to investigate group effects. The behavioural FSCRS reassured self (RS) scores and inadequate self (IS) scores for each individual were also entered as covariates of interest in a separate multiple regression analysis at the random effects level. This was done to predict positive correlations between the behavioural scores and neuronal activity during self-critical or self-reassuring thoughts for the TtS scenarios.

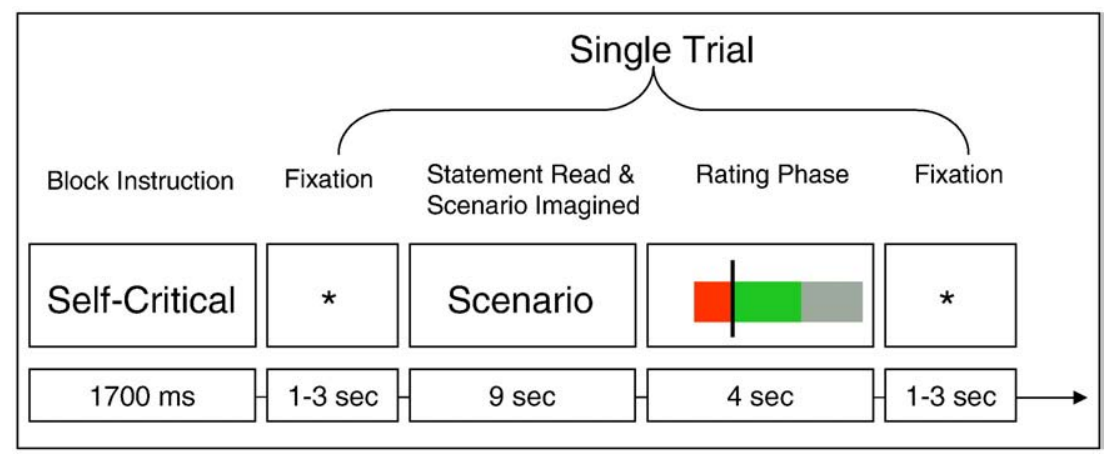

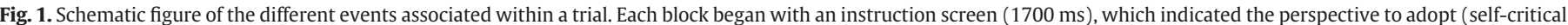

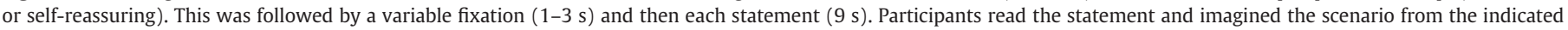

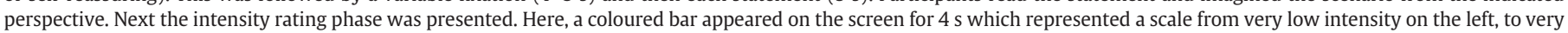
high intensity on the right. Participants pressed a button to indicate how intensely their self-critical or self-reassuring thoughts were. 
Table 1

Brain areas activated in the contrast of: (A) self-criticism during TtS vs. neutral scenarios and (B) self-reassurance during TtS vs. neutral scenarios.

\begin{tabular}{|c|c|c|c|c|c|}
\hline Brain region & $\begin{array}{l}\text { Brodmann's } \\
\text { area }\end{array}$ & p-corrected & Extent & $\begin{array}{l}\text { Coordinates } \\
X Y Z\end{array}$ & $Z$ value \\
\hline \multicolumn{6}{|c|}{ (A) Self-criticism during TtS scenarios vs. neutral scenarios } \\
\hline Dorsomedial FC & BA 8 & $<0.001$ & 460 & $\begin{array}{l}-63252 \\
-62249 \\
62854\end{array}$ & $\begin{array}{l}4.72 \\
3.93 \\
3.67\end{array}$ \\
\hline L IPL & BA 40 & 0.018 & 174 & $-53-4339$ & 4.67 \\
\hline R MTG & BA 38 & 0.006 & 217 & $404-32$ & 4.57 \\
\hline L VLPFC & BA 45 & $<0.001$ & 597 & $\begin{array}{l}-522210 \\
-532019\end{array}$ & $\begin{array}{l}4.36 \\
4.17\end{array}$ \\
\hline L OFC & BA 47 & & & $-4839-2$ & 4.01 \\
\hline L MTG & $\begin{array}{l}\text { BA } 20 \\
\text { BA } 21\end{array}$ & $<0.001$ & 358 & $\begin{array}{l}57-28-14 \\
65-430\end{array}$ & $\begin{array}{l}4.08 \\
4.06\end{array}$ \\
\hline R LatPFC & BA 46 & $0.003^{*}$ & 63 & $\begin{array}{l}562123 \\
542822\end{array}$ & $\begin{array}{l}3.71 \\
3.71\end{array}$ \\
\hline L DLPFC & BA 9 & 0.004 & 234 & $\begin{array}{l}-40635 \\
-381532 \\
-511843\end{array}$ & $\begin{array}{l}3.71 \\
3.62 \\
3.34\end{array}$ \\
\hline R caudate & & $0.022^{*}$ & 15 & 14814 & 3.66 \\
\hline L dorsal AC & BA 32 & $0.022^{*}$ & 20 & 142338 & 3.43 \\
\hline R putatmen & & $0.018^{*}$ & 18 & 1420 & 3.39 \\
\hline (B) Self-reassura & e auring its & ES. Ilas & & & \\
\hline $\begin{array}{l}\text { L temporal } \\
\text { pole/insula }\end{array}$ & BA 38 & $0.002^{*}$ & 81 & $-422-8$ & 3.98 \\
\hline Insula & & & & $-42-4-3$ & 3.21 \\
\hline
\end{tabular}

Clusters significant at $p<0.05$ after statistical correction are reported. Multiple peaks within an extent are shown on subsequent lines.

Coordinates are presented in Talaraich space. L, left, R, right.

* Significant corrected $p$ values shown after SVC.

Activations were thresholded at $p<0.001$ uncorrected (single voxel level), and clusters that survived at $p<0.05$ corrected for multiple comparisons for the entire brain were accepted as significant. As our main focus was on a number of pre-specified regions - the lateral PFC, anterior cingulate, insula and amygdala - for these, we report activations that survive an uncorrected threshold of $p<0.001$ but which are significant at $p<0.05$ when a small volume correction (SVC) (based on a sphere of diameter $10 \mathrm{~mm}$, centred on the peak coordinates as identified by voxel-level thresholding for each contrast of interest) (Worsley et al., 1996) is applied. The set of voxel values for each contrast constituted a statistical parametric map of the $t$ statistic (SPM; $t$ ), which was then transformed to the unit normal distribution, SPM (Z). As SPM coordinates are given in Montreal Neurological Institute (MNI) space, regions were identified by converting the coordinates to Talairach space with a nonlinear transform (Brett et al., 2001).

\section{Results}

\section{Behavioural data}

Scores on the BDI ranged from 0 to 14 (mean $4.29 \pm$ SD 4.24), whilst scores on the CES-D ranged from 2 to 19 (mean 8.94, \pm SD 5.71), indicating that participant's mood scores generally fell within the normal to mildly depressed range (Beck et al., 1988). Scores on the FSCRS for RS ranged from 13 to 32 (mean 23.947, \pm SD 4.44) and for IS ranged from 2 to 23 (mean 12.47, \pm SD 6.27).

\section{fMRI simple main effects}

\section{$B O L D$ response to self-criticism}

To assess the BOLD response to self-criticism, we used the contrast of TtS scenarios minus neutral scenarios (TtS-N) for the self-critical perspective (Table 1$)$. This contrast revealed a significant cluster of activation $(p<0.05$ corrected) in the left lateral prefrontal cortex (PFC) (BA 45) which extended ventrally to the lateral orbitofrontal cortex (OFC; BA 47). Significant clusters were also found in the left dorsolateral PFC (BA 9) and inferior temporal gyrus (ITG; BA 20), extending dorsally to include middle temporal gyrus (MTG; BA 21) and lingual gyrus (BA 19). Additional clusters were found (significant with SVC) in the right lateral PFC (BA 46), putamen, caudate and dorsal anterior cingulate gyrus (dAC; BA 32).

As expected, the reverse contrast of neutral scenarios versus TtS $(\mathrm{N}-\mathrm{TtS})$ for the self-criticism perspective, did not show significant activation ( $p<0.05$ corrected; Fig. 2 ).

Furthermore, we examined the difference in neural response between the two perspectives, using the contrast of self-criticism minus self-reassurance (Table 2). For TtS scenarios, we found greater activation for self-criticism than self-reassurance in the left posterior cingulate (BA 31/23), midline dorsomedial PFC (BA 8), dorsolateral PFC (BA 9), MTG (BA 21) extending ventrally to include ITG (BA 21), cuneus (BA 31/19) and bilateral lingual gyrus (BA 18). Significant clusters were also present in the left VLPFC (BA 46 and 45), right VLPFC (BA 10) and bilateral caudate. The same contrast of selfcriticism versus self-reassurance for neutral scenarios, however, revealed no significant activation ( $p<0.05$ corrected) and only one small cluster (i.e. 5 voxels) was observed in the right VMPFC at the uncorrected level of $p<0.001$ (not reported in the tables).

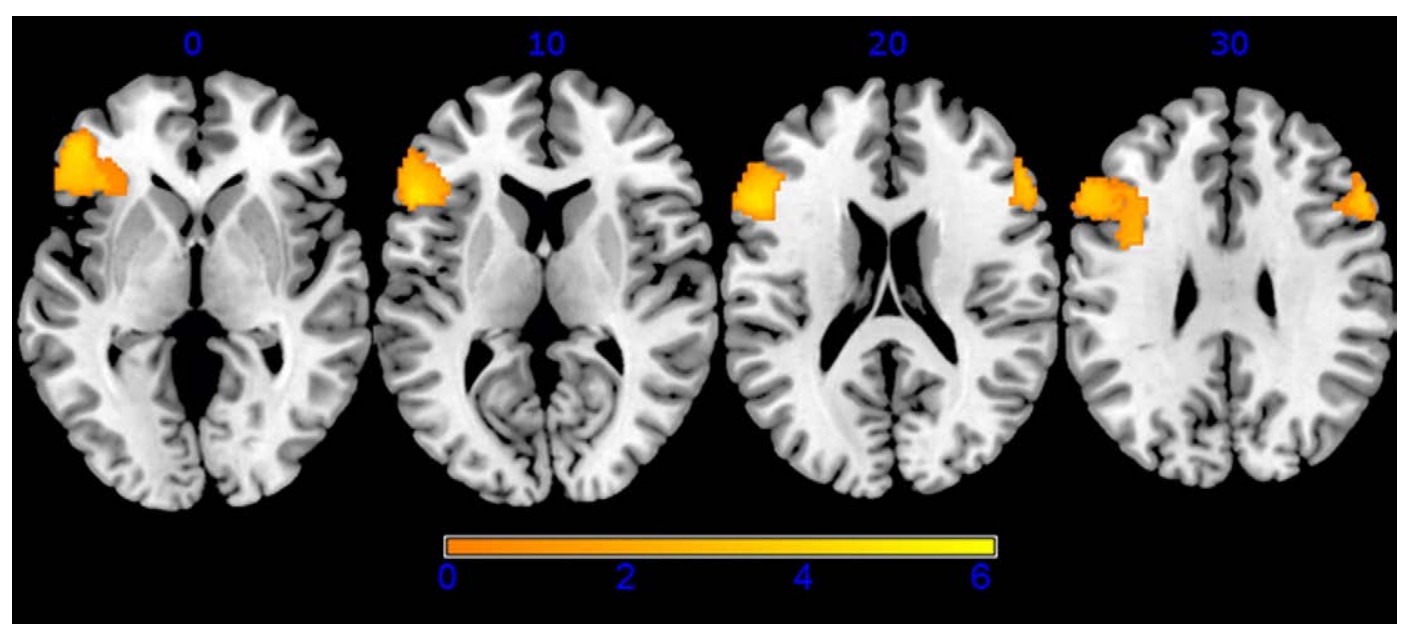

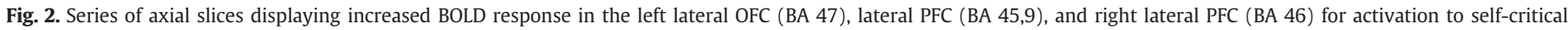

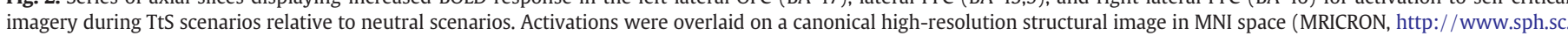
edu/comd/rorden/mricron). The colour bar shows statistical $T$ variation. 
Table 2

Brain areas activated in the contrast of (A) self-criticism vs. self-reassurance during TtS scenarios and (B) self-reassurance vs. self-criticism during TtS scenarios.

\begin{tabular}{|c|c|c|c|c|c|}
\hline Brain region & $\begin{array}{l}\text { Brodmann's } \\
\text { area }\end{array}$ & p-corrected & Extent & $\begin{array}{l}\text { Coordinates } \\
X Y Z\end{array}$ & $Z$ value \\
\hline \multicolumn{6}{|c|}{ (A) Self-criticism vs. self-reassurance during TtS scenarios } \\
\hline L cuneus & BA 17 & $<0.001$ & 8889 & $-18-6711$ & 5.06 \\
\hline \multirow{3}{*}{$\begin{array}{l}\mathrm{R} \text { posterior } \\
\text { cingulate }\end{array}$} & BA 31 & 0.013 & 177 & $24-2833$ & 4.59 \\
\hline & BA 31 & & & 223533 & 4.41 \\
\hline & BA 23 & & & $14-3226$ & 3.51 \\
\hline Midline DMFC & BA 8 & $<0.001$ & 460 & 03249 & 4.72 \\
\hline L MTG & BA 21 & $<0.001$ & 382 & $\begin{array}{l}-50-31-3 \\
-50-30-17 \\
-51-41-1\end{array}$ & $\begin{array}{l}3.97 \\
3.88 \\
3.87\end{array}$ \\
\hline L DLPFC & $\begin{array}{l}\text { BA } 9 \\
\text { BA } 9 \\
\text { BA } 8\end{array}$ & $<0.001$ & 359 & $\begin{array}{l}-542730 \\
-501438 \\
-44648\end{array}$ & $\begin{array}{l}3.95 \\
3.45 \\
3.41\end{array}$ \\
\hline L caudate & & $0.001^{*}$ & 112 & -8411 & 3.84 \\
\hline R caudate & & $0.007^{*}$ & 43 & $\begin{array}{l}241117 \\
16814\end{array}$ & $\begin{array}{l}3.68 \\
3.57\end{array}$ \\
\hline L VLPFC & $\begin{array}{l}\text { BA } 46 \\
\text { BA } 45\end{array}$ & $0.004^{*}$ & 50 & $\begin{array}{lll}-50 & 2613 \\
-50 & 24 & 15\end{array}$ & $\begin{array}{l}3.44 \\
3.15\end{array}$ \\
\hline R VLPFC & BA 10 & $0.03^{*}$ & 10 & $-4052-3$ & 3.39 \\
\hline \multicolumn{6}{|c|}{ (B) Self-reassurance vs. self-criticism during TtS scenarios } \\
\hline $\begin{array}{l}\text { L temporal } \\
\text { pole/insula }\end{array}$ & BA 38 & 0.055 & 128 & $-422-8$ & 4.05 \\
\hline
\end{tabular}

Clusters significant at $p<0.05$ after statistical correction are reported. Multiple peaks within an extent are shown on subsequent lines.

Coordinates are presented in Talaraich space. L, left, R, right.

* Significant corrected $p$ values shown after SVC.

\section{BOLD response to self-reassurance}

To assess the neural response to self-reassurance, we used the contrast of TtS-N when subjects were engaged in self-reassurance. This contrast revealed a cluster of activation (significant with SVC) in the left STG (BA 38), extending dorsally and posteriorly to the insula (Fig. 3; Table 1).

We did not observe any significant ( $p<0.05$ corrected) clusters of activation to the reverse contrast $\mathrm{N}-\mathrm{TtS}$ scenarios whilst participants took the self-reassuring perspective.

Examination of the difference in neuronal response between the perspectives of self-reassurance relative to self-criticism during TtS scenarios (Table 2 ), revealed significantly greater activation $(p<0.05$ corrected) for self-reassurance in the left STG (BA 38)/insula.
Table 3

Summary of brain activations during TtS scenarios that were positively correlated with IS scores, when individuals engaged in (A) self-criticism and (B) self-reassurance.

\begin{tabular}{|c|c|c|c|c|c|}
\hline Brain region & $\begin{array}{l}\text { Brodmann's } \\
\text { area }\end{array}$ & p-corrected & Extent & $\begin{array}{l}\text { Coordinates } \\
X Y Z\end{array}$ & $Z$ value \\
\hline \multicolumn{6}{|c|}{ (A) Correlation with IS scores: self-criticism } \\
\hline L DLPFC & BA 9 & $0.002^{*}$ & 83 & -42933 & 3.89 \\
\hline \multicolumn{6}{|c|}{ (B) Correlation with IS scores: self-reassurance } \\
\hline L DLPFC & BA 9 & $0.009^{*}$ & 41 & -42729 & 3.59 \\
\hline L amyg/hippoc & & $0.048^{*}$ & 3 & $-28-9-18$ & 3.12 \\
\hline
\end{tabular}

Clusters significant at $p<0.05$ after statistical correction are reported. Multiple peaks within an extent are shown on subsequent lines.

Coordinates are presented in Talaraich space. L, left, R, right.

* Significant corrected $p$ values shown after SVC.

The same contrast of self-reassurance versus self-criticism for neutral scenarios revealed no differences, even at the uncorrected threshold of $p<0.001$.

\section{Multiple regression with FSCRS scores for TtS scenarios}

\section{Regression with inadequate self (IS) scores}

During TtS scenarios in which subjects took the self-critical perspective, IS scores were positively correlated with left dorsolateral PFC (BA 9) and middle temporal gyrus (MTG; BA 21) activity (Table 3).

Similarly, for TtS scenarios in which subjects took the selfreassuring perspective, IS scores were positively correlated with left dorsolateral PFC (BA 9), and also with left amygdala/hippocampus activity (Table 3 ).

Regression with reassured self (RS) scores

During TtS scenarios, RS scores positively correlated with activity for self-critical thoughts in a cluster in the right lateral OFC (BA 47) spreading dorsally to VLPFC (BA 45). RS scores were also correlated with left VLPFC (BA 45 and BA 46) (Table 4). Finally, RS scores were positively correlated with neural activity for self-reassuring thoughts (Table 4) in the left (BA 18) and right inferior occipital gyrus (BA 19), left dorsomedial FC (BA 6) and bilateral PFC (BA 46).

\section{Discussion}

This study investigated the difference in the BOLD response to selfcriticism and self-reassurance using a novel fMRI task. We additionally

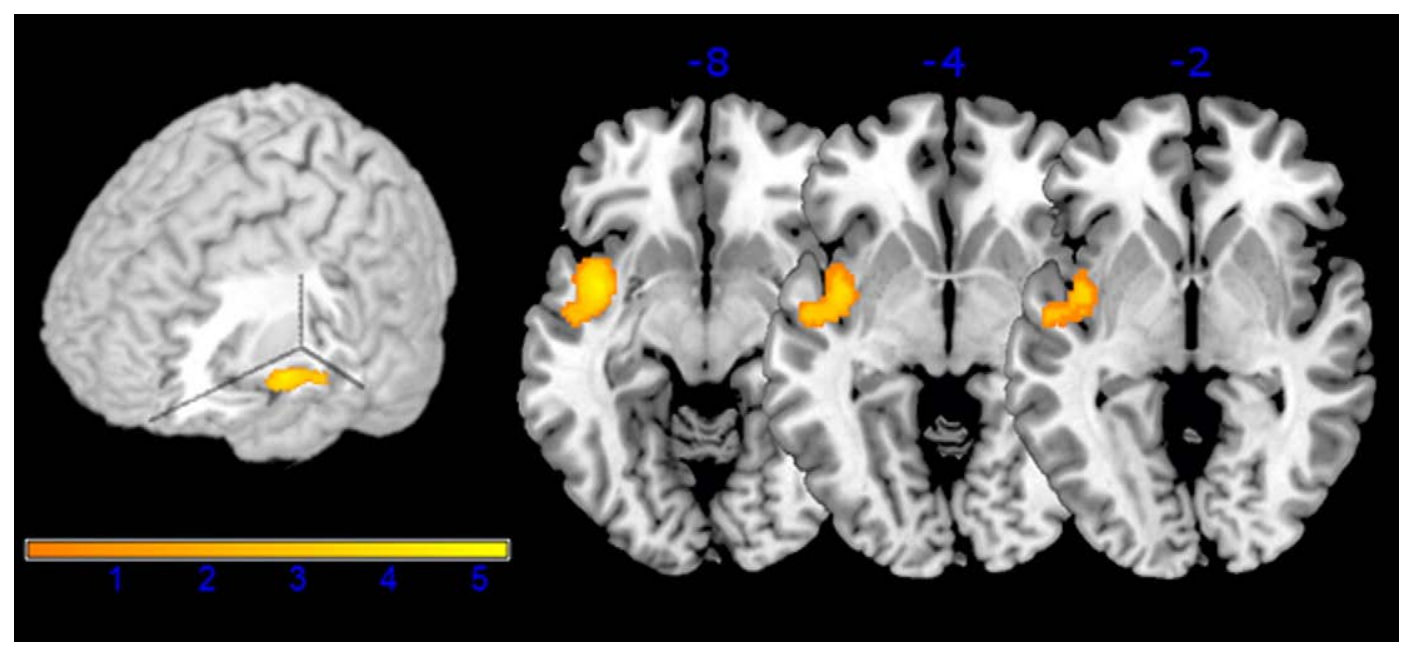

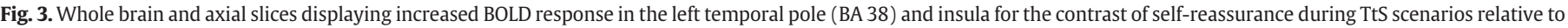

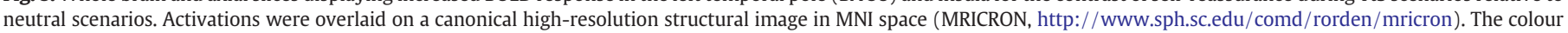
bar shows statistical $T$ variation. 
Table 4

Summary of brain activations during TtS scenarios that were positively correlated with RS scores, when individuals engaged in (A) self-criticism and (B) self-reassurance.

\begin{tabular}{|c|c|c|c|c|c|}
\hline Brain region & $\begin{array}{l}\text { Brodmann's } \\
\text { area }\end{array}$ & p-corrected & Extent & $\begin{array}{l}\text { Coordinates } \\
X Y Z\end{array}$ & $Z$ value \\
\hline \multicolumn{6}{|c|}{ (A) Correlation with RS scores: self-criticism } \\
\hline $\begin{array}{l}\text { L inferior } \\
\text { occipital gyrus }\end{array}$ & BA 18 & $<0.001$ & 4727 & $26-851$ & 4.89 \\
\hline ROFC & BA 47 & $<0.001$ & 549 & $5022-2$ & 4.37 \\
\hline R VLPFC & BA 45 & & & $\begin{array}{lll}50 & 24 & 8 \\
42 & 1817\end{array}$ & $\begin{array}{l}3.94 \\
3.82\end{array}$ \\
\hline L VLPFC & BA 45 & $0.009^{*}$ & 39 & -402215 & 3.66 \\
\hline L VLPFC & BA 46 & $0.024^{*}$ & 13 & 533413 & 3.41 \\
\hline \multicolumn{6}{|c|}{ (B) Correlation with RS scores: self-reassurance } \\
\hline $\begin{array}{l}\text { L inferior } \\
\text { occipital gyrus }\end{array}$ & BA 18 & $<0.000$ & 1402 & $-24-86-1$ & 4.61 \\
\hline $\begin{array}{l}\text { L inferior } \\
\text { occipital gyrus }\end{array}$ & BA 19 & 0.009 & 295 & $-16-9430$ & 4.12 \\
\hline R VLPFC & BA 46 & $0.028^{*}$ & 9 & -582610 & 3.35 \\
\hline L VLPFC & BA 45 & $0.063^{*}$ & 12 & -442215 & 3.32 \\
\hline
\end{tabular}

Clusters significant at $p<0.05$ after statistical correction are reported. Multiple peaks within an extent are shown on subsequent lines.

Coordinates are presented in Talaraich space. L, left, R, right.

* Significant corrected p values shown after SVC.

examined whether the BOLD response observed was correlated with an individual's self-reported tendency to be self-critical or selfreassuring. The analyses revealed extensive lateral PFC activations (bilateral) to self-criticism in addition to striatal (caudate and putamen) and left dAC activations. Self-reassurance on the other hand was associated with significant left superior temporal gyrus and insula activation. Multiple regression analyses further revealed that the dorsolateral PFC and hippocampal/amygdala complex were positively correlated with an individual's tendency to be self-critical, whereas ventrolateral PFC activity and VMPFC were positively correlated with the tendency to be self-reassuring. The implications of these findings for our understanding of the neurophysiology of selfcritical and self-reassuring processes will be discussed in the following sections.

\section{Role of lateral PFC/OFC in self-criticism}

The extensive lateral prefrontal activation observed to the selfcritical perspective was specific to the TtS scenarios and included left LatPFC (BA 45), lateral OFC (BA 47), and DLPFC (BA 9), in addition to right LatPFC (BA 46, BA 44/10). There is much evidence documenting a role for the PFC in approach and withdrawal behaviour, with the lateral PFC in particular, strongly linked with inhibitory behaviour (Konishi et al., 1999; Elliott et al 2000; Davidson et al., 2002; Fassbender et al., 2009).

The DLPFC (BA 9) has additionally been associated with error detection (Chevrier et al., 2007) although a number of studies suggest that it is more commonly associated with the resolution of errors, by subsequent behavioural alteration (Garavan et al., 2002, Kerns et al., 2004, Wittfoth et al., 2009).

Lateral PFC and DLPFC activations found in our study therefore suggest that self-critical thinking is linked to error processing and resolution, followed by the subsequent engagement of inhibitory processes. This corresponds with our psychological understanding of self-criticism as a form of defence behaviour, initiated as an attempt to resolve a perceived error or to limit the social damage incurred by making the error (Gilbert and Irons, 2005).

\section{Role of dorsal AC in self-criticism}

Greater dAC (BA 32) activation was elicited to self-criticism during TtS scenarios than neutral scenarios. DAC activation is often linked in neuroimaging studies to increased monitoring of error and conflict (Bush et al., 2000). As the dAC integrates both motivational information and error signals and is thus thought to influence attention and motor responses (Bush et al., 2000), activation of dAC in our task together with lateral PFC regions would tally with such a role for this region in error monitoring, and the generation of an inhibitory response.

If $\mathrm{dAC}$ activation relates to error monitoring in our task, then the fact that there was no dAC activation present to the self-reassuring perspective during TtS scenarios makes sense, as here we are asking participants to reduce the focus of their attention from their error/ mistake. Furthermore, as dAC activation was only present to selfcriticism and not to self-reassurance, this would indicate the region was not playing its other hypothesised role of self-referencing/selfreflection (Frith and Frith, 1999; Gusnard et al., 2001; Modinos et al., 2009) in the current task.

\section{Role of striatal activity in self-criticism}

Self-criticism can be viewed as a form of self-punishment associated with negative emotions of anger, shame and contempt (Whelton and Greenberg, 2005). Dorsal striatal (caudate and putamen) activity is regularly reported in human imaging studies of both rewards and punishments (Delgado et al., 2000, 2003; Elliott et al., 2004; Knutson et al., 2000, 2001; O'Doherty et al., 2002, 2004; Pagnoni et al., 2002), thus striatal activity in the current task may relate to feelings of self-punishment. For instance, in one of our scenarios we focused on being rejected for a job. Participants here may not have been focusing on whether they made mistakes or errors but on negative characteristics of the self that they are ashamed of and subsequent feelings of self-disappointment or self-dislike. Evoking process of self-criticism in our task thus likely resulted in participants turning their attention 'inward' to induce an intense negative emotional (i.e. self-critical) state.

\section{Additional temporal and occipital gyrus activations to self-criticism}

Further areas of increased activation observed to self-criticism included left inferior and middle temporal gyrus and left lingual gyrus. These activations could be interpreted in terms of enhanced emotional salience of the self-criticism condition (Narumoto et al., 2000).

\section{Role of STG and insula activation in self-reassurance}

Both the contrast of self-reassurance for TtS-N and the contrast of self-reassurance vs. self-criticism (during TtS scenarios) demonstrated a strong cluster of activation in the left temporal pole which extended to include a large portion of the insula. The temporal pole receives projections from the insula, but additionally has strong connections with both the amygdala and OFC; thus it is often referred to as a paralimbic region (see Olson et al., 2007 for review). Activity in the region has been reported in recent fMRI studies investigating complex social emotions. For instance, positive self-conscious emotions of both pride and joy were found to activate the left temporal pole and insula respectively (Takahashi et al., 2008), whilst negative self-conscious emotions of guilt and embarrassment also activated the temporal poles (Takahashi et al., 2004). Self-reassurance could similarly be classed as a complex emotion, involving elements of self-reflection and positive emotions. Self-reassurance could also be expected to call on the retrieval of episodic memories, such as emotional and autobiographical memory for which the temporal poles play an additional role (Fink et al. 1996; Dolan et al. 2000; Sugiura et al. 2006).

The insula is perhaps more clearly defined functionally and is recognised for its importance in the monitoring of one's internal states (Damasio, 1999; Phan et al., 2002, 2004), which are connected to emotional experience, and emerge as conscious feelings (Damasio, 
1994). Insula activation is additionally associated with self-referential tasks (Northoff et al., 2006; Modinos et al., 2009) which most likely relate to the region's role in monitoring internal states. For example, Farb et al. (2007) reported an fMRI study examining different types of self-referencing where half the volunteers, prior to being scanned, took part in a mindfulness meditation course, which involved learning to focus attention on the present moment. The mindfulness group was found to have greater right-sided engagement of the lateral PFC and insula compared to the novice group, when performing selfreferencing focused on the immediate moment, as opposed to self across time. Insula activation in this instance was proposed to relate to current self-awareness based on the integration of internal and external bodily sensory processes.

As the insula is closely connected with ascending internal body signals, the fact that we see insula activation to self-reassurance suggests that this is an inward focused self-related process that calls on assessing one's subjective feelings and arousal state, and relies on bottom up processes of neural activity. Lack of insula activation to self-criticism, in turn, suggests that even though this is also a form of self-reflection, this process may have a more external focus, and relies on top-down neural processing.

Of particular relevance to the current study are the findings of Lutz et al. (2008), who reported that left insula activation is important for the generation of a state of compassion for others, in meditators. Lutz et al. found stronger insula activation in expert meditators (i.e. individuals who regularly practice in engaging in feelings of compassion for others) compared to novice meditators. The fact that we find similar insula activation in our study suggests that generating compassion for the self (generated via self-reassurance) involves the same processes as generating compassion for others. Consequently, our results fit with past findings that both internally generated and externally cued processes can activate the same brain regions.

\section{Multiple regression with reassured self (RS) and inadequate self} (IS) scores

Of note, we found a dorsal/ventral divide in PFC activity between those who scored highly for IS traits and RS traits. High RS scores were positively correlated with neural activations for self-reassuring thoughts and self-critical thoughts in the more ventral portions of the lateral PFC (BA 45, 46). This may indicate that individuals who report high levels of self-reassurance have good self-regulatory control related to emotional processing. The VLPFC is associated with the top-down regulation of limbic regions, implicated in emotional processing (Eippert et al., 2007), and also in studies of emotional reappraisal of negatively valenced stimuli (Johnstone et al., 2007, Ochsner et al., 2004). Lateral OFC (BA 47) activation was also found to positively correlate with high RS scores for the self-critical condition, suggesting that additional recruitment of inhibitory control processes was instigated during self-critical thoughts in these individuals. This finding could be used as evidence to help build towards improved targeting in psychotherapy, as focused therapeutic exercises designed to develop self-reassurance may aid regulation in the face of setbacks (Gilbert and Procter, 2006; Gilbert, 2009).

IS scores, on the other hand, were positively correlated with left DLPFC (BA 9) activation for both self-criticism and self-reassurance i.e. being highly self-critical was associated with greater DLPFC activation. As discussed above, a number of studies suggest that DLPFC is frequently associated with the detection and resolution of errors by behavioural alteration (Garavan et al., 2002; Kerns et al., 2004; Wittfoth et al., 2009), implying that those who have a self-critical nature have greater engagement of error processing and behavioural inhibition. As our task involved individuals reading negative scenarios about themselves, one would expect those who reported higher levels of self-criticism to be less successful at suppressing DLPFC activation - hence why there was also a positive correlation between DLPFC activation and high SC scores for the self-reassurance condition. Consequently, these findings may have broader implications for the neural basis of some neuropsychological disorders, such as anxiety and depression which are characterised by a preoccupation with past and future failure.

Processes of self-reassurance may even be highly threatening to individuals with high trait self-criticism (Gilbert, 2007; Rockilff et al., 2008) accounting for the positive correlation between hippocampal/ amygdala complex activation observed and IS scores for the selfreassuring perspective. Furthermore, a recent fMRI study of emotional reappraisal (Johnstone et al., 2007) found that healthy controls demonstrated decreased amygdala activation when reappraising negative stimuli. However, depressed individuals performing the same task failed to down-regulate the amygdala response to negative stimuli and instead showed increased amygdala activation. In our task, self-critics may similarly be failing to down-regulate the amygdala response to the negative scenarios described in the TtS condition, resulting in the increased amygdala activity observed for these individuals.

\section{Conclusion}

This study investigated the neuronal substrates of self-criticism and self-reassurance. First, we demonstrated that processes of selfcriticism were associated with activity in lateral PFC (including DLPFC) and dorsal AC regions therefore linking self-critical thinking to a form of error processing and resolution, and the subsequent engagement of inhibitory processes. Second, we found activation in the left temporal pole and insula when participants were engaged in self-reassurance, supporting the idea that self-reassurance/selfcompassion engages similar regions to expressing compassion and empathy towards others. Last, we found a dorsal/ventral PFC divide between an individual's tendency to be self-critical or self-reassuring, with dorsal PFC activity positively correlated with high trait selfcriticism and ventral PFC activity positively correlated with high trait self-reassurance. A positive correlation between self-criticism and activity in the DLPFC suggests that error processing and behavioural inhibition are more active in self-critical individuals. Our findings may thus have implications for the neural basis of a range of mood disorders that have self-criticism as a central core, and are characterised by a preoccupation with personal mistakes and failures. Dysfunction of the PFC has frequently been highlighted as a neuropathological feature of mood disorders (Austin et al., 2001; Phillips et al., 2003). The relationship therefore between increased DLPFC activity and high levels of self-criticism may be something that future researchers wish to explore further.

\section{Acknowledgments}

This research was funded by grants from the EPSRC and also by the Lord Dowding Fund.

\section{References}

Austin, M.P., Mitchell, P., Goodwin, G.M., 2001. Cognitive deficits in depression: possible implications for functional neuropathology. Br. J. Psychiatry 178, 200-206.

Babiker, G., Arnold, L., 1997. The Language of Injure: Comprehending Self-mutilation. Leicester. British psychological Society.

Beck, A.T., Ward, C., Mendelson, M., 1961. An inventory for measuring depression. Arch. Gen. Psychiatry 4, 561-571.

Beck, A.T., Rush, A.J., Shaw, B.F., Emery, G., 1979. Cognitive Therapy of Depression. J. Wiley \& Sons, New York.

Beck, A.T., Steer, R.A., Garbin, M.G., 1988. Psychometric properties of the Beck Depression Inventory: twenty five years of evaluation. Clin. Psychol. Rev. 8, 77100.

Brett, M., Christoff, K., Cusack, R., Lancaster, J., 2001. Using the Talairach atlas with the MNI template. NeuroImage 13 (6), S85.

Brewin, C.R., 2003. Post-traumatic Stress Disorder: Malady or Myth? Yale University Press, New Haven. 
Blatt, S., Zuroff, D., 1992. Interpersonal relatedness and self-definition. Two prototypes for depression. Clin. Psychol. Rev. 12, 527-562.

Bush, G., Luu, P., Posner, M.I., 2000. Cognitive and emotional influences in anterior cingulate cortex. Trends Cogn. Sci. 4, 215-222.

Chevrier, A.D., Noseworthy, M.D., Schachar, R., 2007. Dissociation of response inhibition and performance monitoring in the stop signal task using event-related fMRI. Hum. Brain Mapp. 28 (12), 1347-1358.

Cox, B.J., Rector, N.A., Bagby, R.M, Swinson, R.P., Levitt, A.J., Joffe, R.T., 2000. Is self criticism unique for depression: a comparison with social phobia. J. Affect. Disord. $57,223-228$.

Damasio, A.R., 1994. Descartes' error and the future of human life. Sci. Am. 271, 144.

Damasio, A.R., 1999. The Feeling of What Happens: Body and Emotion in the Making of Consciousness. Hardcourt Brace, New York, NY.

Davidson, R.J., Pizzagalli, D., Nitschke, J.B., Putnam, K., 2002. Depression: perspectives from affective neuroscience. Annu. Rev. Psychol. 53, 545-574.

Delgado, M.R., Nystrom, L.E., Fissell, C., Noll, D.C., Fiez, J.A., 2000. Tracking the hemodynamic responses to reward and punishment in the striatum. J. Neurophysiol. 84 (6), 3072-3077.

Delgado, M.R., Locke, H.M., Stenger, V.A., Fiez, J.A., 2003. Dorsal striatum responses to reward and punishment: effects of valence and magnitude manipulations. Cogn. Affect. Behav. Neurosci. 3 (1), 27-38.

Dolan, R.S., Lane, R., Chua, P., Fletcher, P., 2000. Dissociable temporal lobe activations during emotional episodic memory retrieval. Neurolmage 11, 203-209.

Elliott, R., Dolan, R.J., Frith, C.D., 2000. Dissociable functions in the medial and lateral orbitofrontal cortex: evidence from human neuroimaging studies. Cereb. Cortex 3, 308-317.

Elliott, R., Newman, J.L., Longe, O.A., Deakin, J.F., 2004. Instrumental responding for rewards is associated with enhanced neuronal response in subcortical reward systems. Neurolmage 3, 984-990.

Eippert, F., Veit, R., Weiskopf, N., Erb, M., Birbaumer, N., Anders, S., 2007. Regulation of emotional responses elicited by threat-related stimuli. Hum. Brain Mapp. 28 (5), 409-423.

Farb, N.A., Segal, Z.V., Mayberg, H., Bean, J., McKeon, D., Fatima, Z., Anderson, A.K., 2007. Attending to the present: mindfulness meditation reveals distinct neural modes of self-reference. Soc. Cogn. Affect. Neurosci. 2 (4), 313-322.

Fassbender, C., Hester, R., Murphy, K., Foxe, J.J., Foxe, D.M., Garavan, H., 2009. Prefrontal and midline interactions mediating behavioral control. Eur. J. Neurosci. 29 (1), 181-187.

Frith, C.D., Frith, U., 1999. Interacting minds-a biological basis. Science 286 (5445), 1692-1695.

Fink, G.R., Markowitsch, H.J., Reinkemeier, M., Bruckbauer, T., Kessler, J., Heiss, W.D., 1996. Cerebral representation of one's own past: neural networks involved in autobiographical memory. J. Neurosci. 16 (13), 4275-4282.

Garavan, H., Ross, T.J., Murphy, K., Roche, R.A., Stein, E.A., 2002. Dissociable executive functions in the dynamic control of behavior: inhibition, error detection, and correction. NeuroImage 17 (4), 1820-1829.

George, M.S., Ketter, T.A., Parekh, P.I., Horwitz, B., Hercovitch, P., Post, R.M., 1995. Brain activity during transient sadness and happiness in health women. Am. J. Psychiatry. 152, 341-351.

Gilbert, P., 1989. Human Nature and Suffering. Lawrence Erlbaum Associates, Hove.

Gilbert, P., 2000. Social mentalities: internal 'social' conflicts and the role of inner warmth and compassion in cognitive therapy. In: Gilbert, P., Bailey, K.G. (Eds.), Genes on the Couch: Explorations in Evolutionary Psychotherapy. Psychology Press, Hove, pp. 118-150.

Gilbert, P., 2007. Psychotherapy and Counselling for Depression, 3rd edn. Sage, London.

Gilbert, P., 2009. The Compassionate Mind. A New Approach to the Challenges of Life. Constable \& Robinson, London.

Gilbert, P., Miles, J.N.V., 2000. Sensitivity to put-down: its relationship to perceptions of shame, social anxiety, depression, anger and self-other blame. Pers. Individ. Differ. 29, 757-774

Gilbert, P, Irons, C., 2005. Focused therapies and compassionate mind training for shame and self-attacking. In: Gilbert, P. (Ed.), Compassion: Conceptualisations, Research and Use in psychotherapy. Routledge, London, pp. 263-325.

Gilbert, P., Procter, S., 2006. Compassionate mind training for people with high shame and self-criticism: a pilot study of a group therapy approach. Clin. Psychol. Psychother. 13, 353-379.

Gilbert, P., Clarke, M., Hempel, S., Miles, J.N.V., Irons, C., 2004. Criticising and reassuring oneself: an exploration of forms, styles and reasons in female students. Br. J. Clin. Psychol. 43, 31-50.

Gusnard, D.A, Akbudak, E., Shulman, G.L., Raichle, M.E., 2001. Medial prefrontal cortex and self-referential mental activity: relation to a default mode of brain function. Proc. Natl. Acad. Sci. 98 (7), 4259-4264.

Hooley, J.M., Gruber, S.A., Scott, L.A., Hiller, J.B., Yurgelun-Todd, DA., 2005. Activation in dorsolateral prefrontal cortex in response to maternal criticism and praise in recovered depressed and healthy control participants. Biol. Psychiatry 57 (7), 809-812.

Irons, C., Gilbert, P., Baldwin, M.W., Baccus, J., Palmer, M., 2006. Parental recall, attachment relating and self attacking/self-reassurance: their relationship with depression. Br. J. Clin. Psychol. 45, 297-308.

Johnson, S.C., Baxter, L.C., Wilder, S.W., Pipe, J.G., Heiserman, J.E., et al., 2002. Neural correlates of self-reflection. Brain 125, 1808-1814

Johnson, M.K., Raye, C.L., Mitchell, K.J., Touryan, S.R., Greene, E.J., et al., 2006. Dissociating medial frontal and posterior cingulate activity during self-reflection. Soc. Cogn. Affect. Neurosci. 1, 56-64.

Johnstone, T., van Reekum, C.M., Urry, H.L., Kalin, N.H., Davidson, R.J., 2007. Failure to regulate: counterproductive recruitment of top-down prefrontal-subcortical circuitry in major depression. J. Neurosci. 27 (33), 8877-8884.
Kerns, J.G., Cohen, J.D., MacDonald III, A.W., Cho, R.Y., Stenger, V.A., Carter, C.S., 2004 Anterior cingulate conflict monitoring and adjustments in control. Science 303 (5660), 1023-1026.

Knutson, B., Westdorp, A., Kaiser, E., Hommer, D., 2000. FMRI visualization of brain activity during a monetary incentive delay task. Neurolmage 12 (1), 20-27.

Knutson, B., Adams, C.M., Fong, G.W., Hommer, D., 2001. Anticipation of increasing monetary reward selectively recruits nucleus accumbens. J. Neurosci. 21 (RC159), 1-5

Konishi, S., Nakajima, K., Uchida, I., Kikyo, H., Kameyama, M., Miyashita, Y., 1999. Common inhibitory mechanism in human inferior prefrontal cortex revealed by event-related functional MRI. Brain 122 (5), 981-991.

Leary, M.R., Tate, E.B., Adams, C.E., Allen, A.B., Hancock, J., 2007. Self-compassion and reactions to unpleasant self-relevant events: the implications of treating oneself kindly. J. Pers. Soc. Psychol. 92, 887-904.

LeDoux, J., 1998. Fear and the brain: where have we been, and where are we going? Biol Psychiatry 44 (12), 1229-1238.

LeDoux, J.E., 2000. Emotion circuits in the brain. Annu. Rev. Neurosci. 23, 155-184.

Lee, D.A., 2005. The perfect nurturer: a model to develop a compassionate mind within the context of cognitive therapy. In: Gilbert, P. (Ed.), Compassion: Conceptualisations, Research and Use in Psychotherapy. Brunner Routledge, London, pp. 326-351.

Lutz, A., Brefczynski-Lewis, J., Johnstone, T, Davidson, R.J., 2008. Regulation of the theme neural circuitry of emotion by compassion meditation: effects of the meditative expertise. PLoS One 3, 1-5.

Masten, A.S., 2001. Ordinary magic: resilience processes in development. Am. Psychol 56, 227-238.

Mikulincer, M, Shaver, P.R., 2007. Attachment in Adulthood: Structure, Dynamics, and Change. Guilford, New York.

Miller, E.K., Cohen, J.D., 2001. An integrative theory of prefrontal cortex function. Annu. Rev. Neurosci. 24, 167-202.

Modinos, G., Ormel, J., Aleman, A., 2009. Activation of anterior insula during selfreflection. PLoS ONE 4 (2), e4618.

Narumoto, J., Yamada, H., Iidaka, T., Sadato, N., Fukui, K., Itoh, H., Yonekura, Y., 2000. Brain regions involved in verbal or non-verbal aspects of facial emotion recognition. NeuroReport 11, 2571-2576.

Neff, K.D., 2003. Self-compassion: an alternative conceptualization of a healthy attitude toward oneself. Self \& Identity 2, 85-102.

Northoff, G., Heinzel, A., de Greck, M., Bermpohl, F., Dobrowolny, H., Panksepp, J., 2006. Self-referential processing in our brain-a meta-analysis of imaging studies on the self. Neurolmage 31 (1), 440-457.

O'Doherty, J.P., Deichmann, R., Critchley, H.D., Dolan, R.J., 2002. Neural responses during anticipation of a primary taste reward. Neuron 33, 815-826.

O'Doherty, J., Dayan, P., Schultz, J., Deichmann, R., Friston, K., Dolan, R.J., 2004 Dissociable roles of ventral and dorsal striatum in instrumental conditioning. Science 304 (5669), 452-454.

Olson, I.R, Plotzker, A., Ezzyat, Y., 2007. The enigmatic temporal pole: a review of findings on social and emotional processing. Brain 30 (7), 1718-1731.

Ochsner, K.N., Ray, R.D., Cooper, J.C., Robertson, E.R., Chopra, S., Gabrieli, J.D., Gross, J.J. 2004. For better or for worse: neural systems supporting the cognitive down- and up-regulation of negative emotion. NeuroImage 23 (2), 483-499.

Pagnoni, G., Zink, C.F., Montague, P.R., Berns, G.S., 2002. Activity in human ventral striatum locked to errors of reward prediction. Nat. Neurosci. 5 (2), 97-98.

Phan, K.L, Wager, T., Taylor, S.F., Liberzon, I., 2002. Functional neuroanatomy of emotion: a meta-analysis of emotion activation studies in PET and fMRI. Neurolmage 16 (2), 331-348.

Phan, K.L., Wager, T.D., Taylor, S.F., Liberzon, I., 2004. Functional neuroimaging studies of human emotions. CNS Spectr. 9 (4), 258-266.

Phillips, M.L., Drevets, W.C., Rauch, S.L., Lane, R., 2003. Neurobiology of emotion perception II: implications for major psychiatric disorders. Biol. Psychiatry 54, 515-528.

Radloff, L.S., 1977. The CES-D scale: a self-report depression scale for research in the general population. Appl. Psychol. Meas. 1, 385-401.

Rector, N.A., Bagby, R.M., Segal, Z.V., Joffe, R.T, Levitt, A., 2000. Self-criticism and dependency in depressed patients treated with cognitive therapy or pharmacotherapy. Cogn. Ther. Res. 24, 571-584.

Rockliff, H., Gilbert, P., McEwan, K., Lightman, S., Glover, D., 2008. A pilot exploration of heart rate variability and salivary cortisol responses to compassion-focused imagery. J. Clin. Neuropsychiatry 5, 132-139.

Sugiura, M., Sassa, Y., Watanabe, J., Akitsuki, Y., Maeda, Y., Matsue, Y., Fukuda, H. Kawashima, R., 2006. Cortical mechanisms of person representation: recognition of famous and personally familiar names. NeuroImage 31 (2), 853-860.

Takahashi, H., Yahata, N., Koeda, M., Matsuda, T., Asai, K., Okubo, Y., 2004. Brain activation associated with evaluative processes of guilt and embarrassment: an fMRI study. NeuroImage 23 (3), 967-974.

Takahashi, H., Matsuura, M. Koeda, M., Yahata, N., Suhara, T., Kato, M., Okubo, Y, 2008. Brain activations during judgments of positive self-conscious emotion and positive basic emotion: pride and joy. Cereb. Cortex 18 (4), 898-903.

Tangney, J.P., Dearing, R.L., 2002. Shame and Guilt. Guilford Press, New York.

Teasdale, J.D, Cox, 2001. Dysphoria: self-devaluative and affective components in recovered depressed and never depressed controls. Psychol. Med. 31, 1311-1316.

Whelton, W.J., Greenberg, L.S., 2005. Emotion in self-criticism. Pers. Individ. Differ. 38 , 1583-1595.

Wittfoth, M., Schardt, D.M., Fahle, M., Herrmann, M., 2009. How the brain resolves high conflict situations: double conflict involvement of dorsolateral prefrontal cortex. NeuroImage 44 (3), 1201-1209.

Worsley, K.J., Marrett, S., Neelin, P., Vandal, A.C., Friston, K.J., Evans, A.C., 1996. A unified statistical approach for determining significant signals in images of cerebral activation. Hum. Brain Mapp. 4, 58-73.

Zuroff, D.C., Koestner, R., Powers, T.A., 1994. Self-criticism at age 12: a longitudinal study of adjustment. Cogn. Ther. Res. 18, 367-385. 